\title{
Multiple roles of inhibition in the olfactory system
}

\author{
Maxim Bazhenov \\ From 1st International Workshop on Odor Spaces \\ Hannover, Germany. 4-7 September 2013
}

Olfactory stimuli are vast in number and defy simple description. In contrast to light or sound, no low dimensional basis suffices to represent chemical stimuli. And yet, the olfactory system maps the complex and highdimensional world of chemical stimuli into unique and reproducible ensembles of neuronal activity. This mapping includes multilevel processing and involves complex strategies for information encoding. In the insect, olfactory receptor neurons (ORNs) synapse onto a smaller group of excitatory projection neurons (PNs) and inhibitory local neurons (LNs) in the antennal lobe (AL). The odor information is then transferred to the mushroom body $(\mathrm{MB})$, a structure analogous to the olfactory cortex and where olfactory memories are formed. Inhibitory circuits of the AL and the MB shape the odor representation as it progresses through the olfactory system.

Drawing on results obtained with biophysical network models, I will discuss the role played by feedback and feedforward inhibition in shaping odor-driven responses of olfactory neurons. Using model of the locust olfactory system we described the role of the fast feedback GABAa-type inhibition in generating odor triggered AL oscillations. Our study suggested that the transient nature of PN synchronization could be explained by variations in inhibitory drive from inhibitory LNs to specific groups of PNs over the duration of the odor-elicited response and we established a relationship between an important structural property of an inhibitory AL network, its colorings, and the dynamics it constrains. We showed that our description allows the explicit identification of the groups of inhibitory interneurons in the insect AL that switch, during odor stimulation, between activity and quiescence to provide transiently synchronized response of the PNs. This description optimally matches the perspective of the downstream KCs looking for

University of California Riverside, Riverside, CA, USA synchrony in ensembles of pre-synaptic cells. We further found that feedback inhibition provided by the giant GABAergic neuron (GGN) is sufficient to maintain sparse but varied excitation in the $\mathrm{KCs}$ across range of odor concentrations. Our study revealed how multiple forms of synaptic inhibition differentially contribute to process information in the olfactory system.

Published: 16 April 2014

doi:10.1186/2044-7248-3-S1-O24

Cite this article as: Bazhenov: Multiple roles of inhibition in the olfactory system. Flavour 2014 3(Suppl 1):O24.
Submit your next manuscript to BioMed Central and take full advantage of:

- Convenient online submission

- Thorough peer review

- No space constraints or color figure charges

- Immediate publication on acceptance

- Inclusion in PubMed, CAS, Scopus and Google Scholar

- Research which is freely available for redistribution
() Biomed Central 